\title{
Селивановаит, $\mathrm{NaTi}_{3}(\mathrm{Ti}, \mathrm{Fe}, \mathrm{Na})_{4}\left[\left(\mathrm{Si}_{2} \mathrm{O}_{7}\right)_{2}(\mathrm{O}, \mathrm{OH})_{4}\left(\mathrm{OH}, \mathrm{H}_{2} \mathrm{O}\right)_{4}\right] \cdot \mathrm{nH}_{2} \mathrm{O},-$ новый мурманитоподобный гетерофиллосиликат и закономерности его образования в эвдиалитовых луявритах Ловозёрского массива
}

\author{
Пахомовский Я.А. ${ }^{1,2}$, Паникоровский Т.Л. ${ }^{3}$, Яковенчук В.Н. ${ }^{1,2}$, Калашников А.О. ${ }^{1,2}$, \\ Михайлова Ю.А. ${ }^{1,2}$, Кривовичев С.В. ${ }^{2}$, Иванюк Г.Ю. ${ }^{1,2}$ \\ ${ }^{1}$ Геологический институт ФИЦ КНЦ РАН, Anamumbl,pakhom@geoksc.apatity.ru, \\ kalashnikov@geoksc.apatity.ru; yakovenchuk@geoksc.apatity.ru;ylya_korchak@mail.ru \\ ${ }^{2}$ Центр наноматериаловедения ФИЦКНЦРАН, Anamumbl,g.ivanyuk@gmail.com; skrivovi@mail.ru \\ ${ }^{3}$ Лаборатория природоподобных технологий и техносферной безопасности Арктики ФИЦ КНЦ \\ PAH, Anamumbl,taras.panikorovsky@spbu.ru
}

Аннотация. Приведена краткая характеристика нового гетерофиллосиликата селивановаита, образование которого связано с гидротермальным изменением породообразующего мурманита высококальциевыми железистыми растворами, сформировавшимися в ходе метасоматической переработки ксенолитов оливиновых базальтов и их туфов щелочными расплавами/флюидами. Для трансформации мурманита в селивановаит требуется нетривиальная перестройка кристаллической структуры по схеме «монокристалл в монокристалл».

Ключевые слова: селивановаит, мурманит, структурная трансформация, гидротермальное изменение.

\section{Selivanovaite, $\mathrm{NaTi}_{3}(\mathrm{Ti}, \mathrm{Fe}, \mathrm{Na})_{4}\left[\left(\mathrm{Si}_{2} \mathrm{O}_{7}\right)_{2}(\mathrm{O}, \mathrm{OH})_{4}\left(\mathrm{OH}, \mathrm{H}_{2} \mathrm{O}\right)_{4}\right] \cdot \mathrm{nH}_{2} \mathrm{O},-$ a new murmanite-like zirconosilicate and features of its formation in eudialyte lujavrite of the Lovozero massif}

\author{
Pakhomovsky Ya.A. ${ }^{1,2}$, Panikorovskii T.L. ${ }^{3}$, Yakovenchuk V.N. ${ }^{1,2}$, Kalashnikov A.O. ${ }^{1,2}$, \\ Mikhailova Yu.A. ${ }^{1,2}$, Krivovichev S.V. ${ }^{2}$, Ivanyuk G.Yu. ${ }^{1,2}$ \\ ${ }^{1}$ Geological institute FRC KSC RAS, Apatity, pakhom@geoksc.apatity.ru; kalashnikov@geoksc.apatity. \\ ru;yakovenchuk@geoksc.apatity.ru; ylya_korchak@mail.ru \\ ${ }^{2}$ Nanomaterials ResearchCenterFRCKSCRAS,Apatity,g.ivanyuk@gmail.com; skrivovi@mail.ru \\ ${ }^{3}$ Laboratory of geo-insired technologies and environmental safety of Arctic region FRC KSC RAS, Apatity, \\ taras.panikorovsky@spbu.ru
}

\begin{abstract}
The paper provides a brief description of a new heterophillosilicate selivanovaite, the formation of which can be assigned to the hydrothermal change of rock-forming murmanite by Ca-Fe-rich solutions formed during fenitization of xenoliths of olivine basalts and their tuffs. For the transformation of murmanite into selivanovite, a nontrivial restructuring of the crystal structure according to the «single crystal to single crystal» scheme is required.

Key words: selivanovaite, murmanite, structural transformation, hydrothermal alteration.
\end{abstract}

Селивановаит, $(\mathrm{Na}, \mathrm{Ca})_{3}(\mathrm{Ti}, \mathrm{Fe})_{5}\left[\mathrm{Si}_{4} \mathrm{O}_{17}(\mathrm{OH})_{5}\right] \bullet n \mathrm{H}_{2} \mathrm{O}, P \overline{1}, a=8.673(5), b=8.694(3), c=12.21(1) \AA$, $\alpha=92.70(5), \beta=108.46(7), \gamma=105.40(4)^{\circ}, \mathrm{V}=833(1) \AA^{3}, \mathrm{Z}=2$ - новый слоистый титаносиликат группы мурманита из эвдиалитовых луявритов Ловозёрского массива (Pakhomovsky et al., 2018). Он обнаружен в керне нескольких скважин, пробуренных в пределах Аллуайвского участка Ловозёрского эвдиалитового месторождения (рис. $1 \mathrm{a}$, б), и назван в честь Е.А. Селивановой, заведующего лабораторией ГИ КНЦ РАН, за её вклад в изучение минералогии щелочных комплексов. Селивановаит образует тёмно-оранжевые пластинчатые метакристаллы (до 8 мм в диаметре) с многочисленными пойкилитовыми включениями эгирина и магнезиоарфведсонита (рис. 2 a) в ассоциации с породообразующими микроклин-пертитом, нефелином, содалитом и натролитом, а также акцессорными лампрофиллитом, мурманитом, лопаритом-(Сe), пирохлором, торитом, анатазом, баритом, рабдофаном-(Се), пирротином, халько-пиритом, пиритом, хлорбартонитом, джерфишеритом, сфалеритом и лёллингитом.

Средний химический состав селивановаита ( $\mathrm{Na}_{2} \mathrm{O} 5.45 ; \mathrm{MgO} 0.59 ; \mathrm{Al}_{2} \mathrm{O}_{3} 0.04 ; \mathrm{SiO}_{2} 25.55$; $\mathrm{K}_{2} \mathrm{O}$ 0.63; $\mathrm{CaO}$ 1.68; $\mathrm{TiO}_{2}$ 31.17; $\mathrm{MnO}$ 2.64; $\mathrm{FeO} 6.63 ; \mathrm{ZrO}_{2} 2.31 ; \mathrm{Nb}_{2} \mathrm{O}_{5} 6.69 ; \mathrm{H}_{2} \mathrm{O} 17.0$ мас. \%) соответ- 

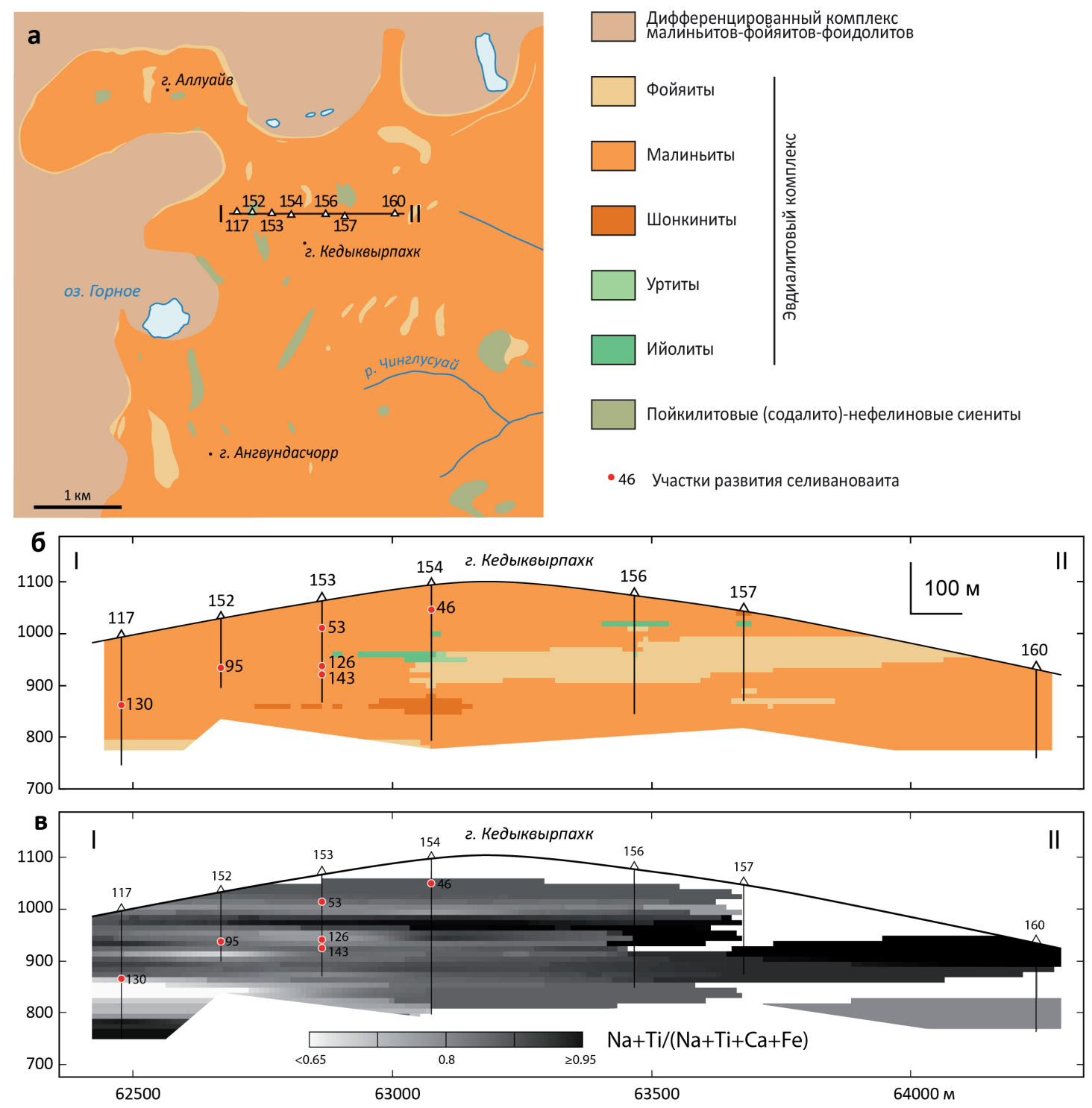

Рис. 1. Аллуайвский участок Ловозёрского эвдиалитового месторождения (а), его разрез по линии I-II (б) и распределение химического состава мурманита (apfu) в этом разрезе (в).

Fig. 1. The Alluaiv part of the Lovozero Eudialyte Deposit (a), its section along the I-II line (б) and distribution of chemical composition of murmanite (apfu) along the section (в).

ствует эмпирической формуле $\left(\mathrm{Na}_{1.65} \mathrm{Ca}_{0.28} \mathrm{Mn}_{0.35} \mathrm{Zr}_{0.18} \mathrm{Mg}_{0.14} \mathrm{~K}_{0.13}\right)_{\Sigma 2.73}\left(\mathrm{Ti}_{3.67} \mathrm{Fe}^{2+}{ }_{0.78} \mathrm{Nb}_{0.47} \mathrm{Al}_{0.01}\right)_{\Sigma 4.93}\left[\mathrm{Si}_{4} \mathrm{O}_{17.66}\right.$ $\left.(\mathrm{OH})_{3.34}\right] \cdot 7.2 \mathrm{H}_{2} \mathrm{O}$, однако, в целом, состав минерала варьирует в весьма широких пределах. Сопоставление состава сосуществующих мурманита и селивановаита показало (рис. 2б), что при переходе от первого ко второму происходит линейное увеличение содержания железа за счёт титана и натрия по схеме: $2 \mathrm{Na}^{+}+\mathrm{Ti}^{4+} \leftrightarrow \square+2 \mathrm{Fe}^{3+}$ и/или $\mathrm{Na}^{+}+\mathrm{Ti}^{4+} \leftrightarrow \mathrm{Ca}^{2+}+\mathrm{Fe}^{3+},-$ так что можно предположить, что селивановаит является продуктом соответствующих катионообменных реакций. В пользу этого косвенно свидетельствует и приуроченность селивановаита к участкам развития мурманита с повышенным содержанием Са и Fe (рис. 1 в).

В основе структуры селивановаита (рис. 3) лежат характерные для минералов группы мурманита титаносиликатные (TS) $\mathrm{HOH}$-пакеты $\left[N_{2} M_{5} \mathrm{Si}_{4} \mathrm{O}_{18}(\mathrm{OH})_{3}\right], M=\mathrm{Ti}, \mathrm{Nb}, \mathrm{Fe}$ и $\mathrm{Mn}, N=\mathrm{Na}, \mathrm{K}, \mathrm{Ca}$, $\mathrm{Mn}, \mathrm{Mg}$ и $\mathrm{Zr}$, составленные из октаэдрических $O$ и гетерополиэдрических $H$ слоёв, а между $H O H$ пакетами располагаются межслоевые $I$-блоки из изолированных $N$-октаэдров и молекул воды между ними. Вместе с тем, структура селивановаита существенно отличается от таковой мурманита не 

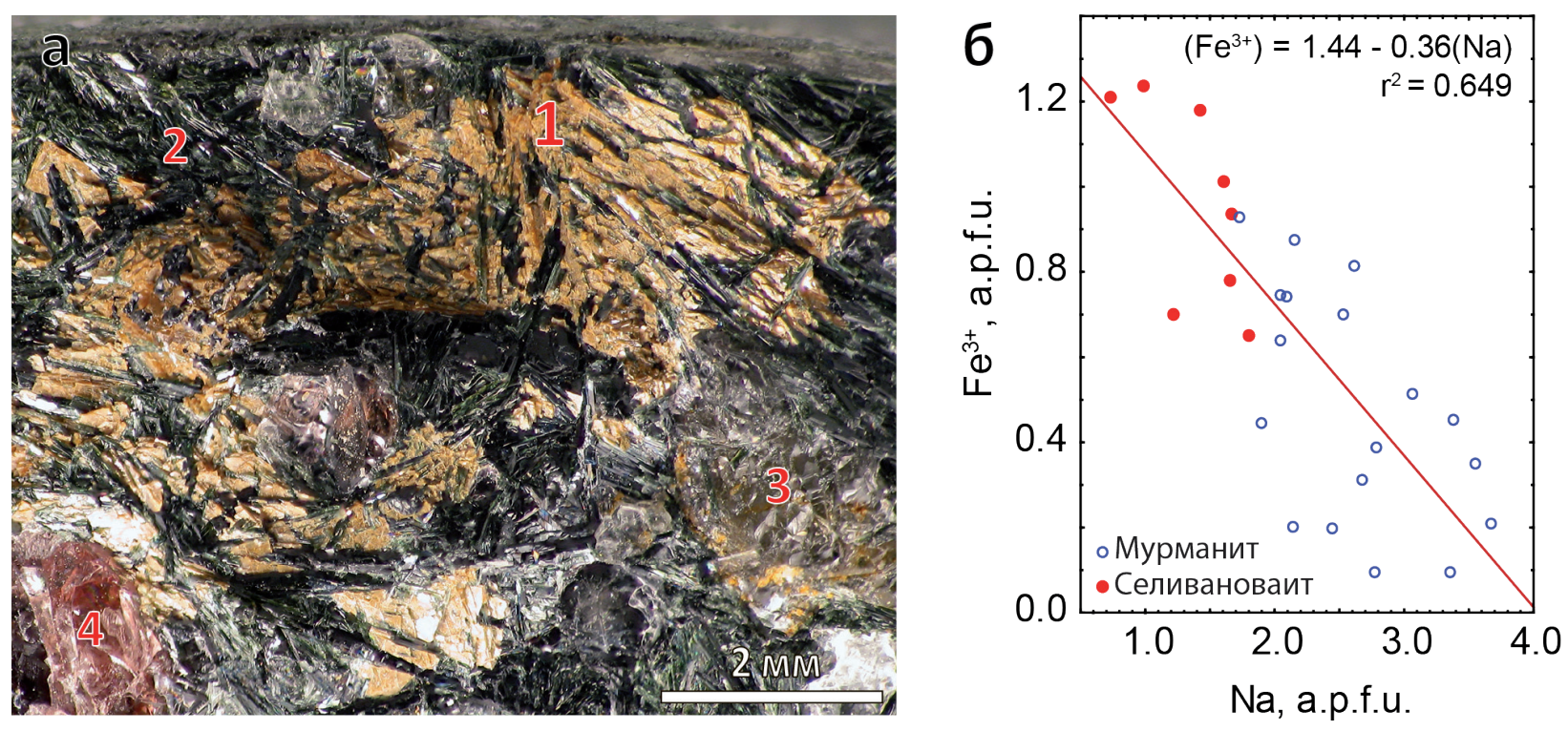

Рис. 2. Метакристаллы селивановаита (1) в эвдиалитовом луяврите (а) и соотношение содержания $\mathrm{Na}$ и Fe в составе сосуществующих мурманита и селивановаита (б). 2 - эгирин, 3 - нефелин, 4 - манганоэвдиалит.

Fig. 2. Selivanovaite metacrysts (1) in eudialyte lujavrite (a) and relation between contents of $\mathrm{Na}$ and Fe in coexisting selivanovaite and murmanite (б). 2 - aegirine, 3 - nepheline, 4 - manganoeudialyte.

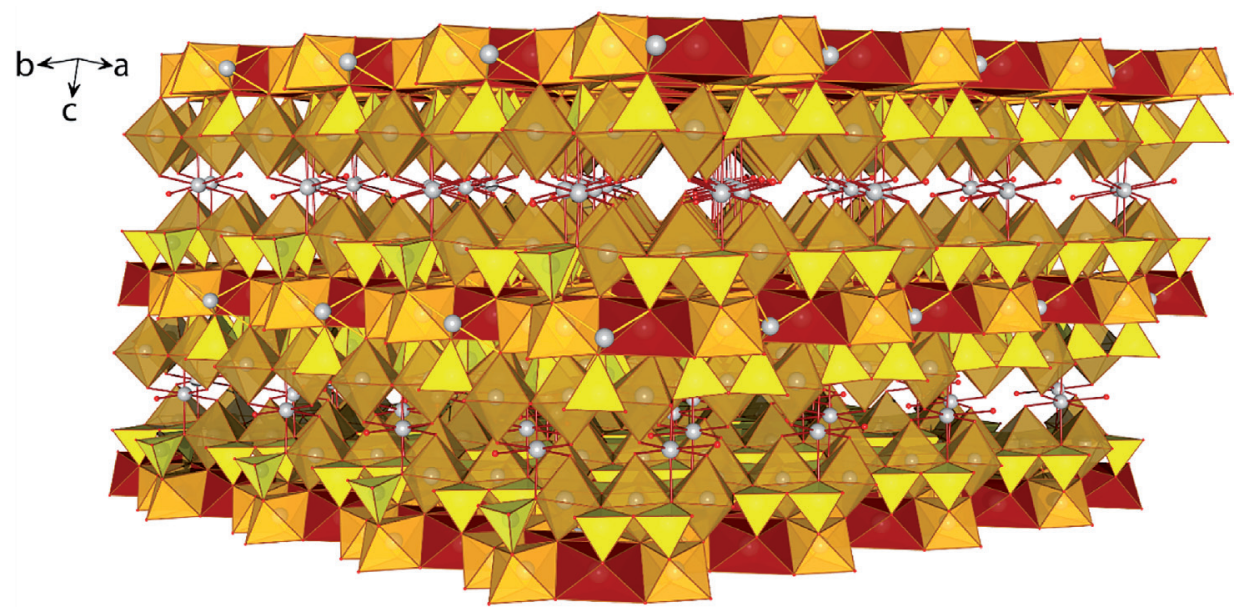

Рис. 3. Кристаллическая структура селивановаита. Серые шарики - частично заполненные позиции $M^{O} 4$ и $A^{P} 1$, жёлтые тетраэдры - $\mathrm{SiO}_{4}$, бледно-коричневые октаэдры - $M^{H} 1, M^{H} 2, M^{H} 3$, оранжевые октаэдры - $M^{O} 1, M^{\circ} 2$, красные октаэдры - $M^{O} 3$.

Fig. 3. Crystal structure of selivanovaite. Half-occupated $M^{O} 4$ and $A^{P} 1$ sites represented by grey spheres, $\mathrm{SiO}_{4}$ tetrahedra are yellow, $M^{H} 1, M^{H} 2, M^{H} 3$ octahedra - pale brown, $M^{O} 1, M^{O} 2$ - orange, $M^{O} 3$ - red.

только строением межслоевого I-пакета, но и расположением полиэдров в октаэдрическом $O$ и гетерополиэдрических $Н$ слоях титаносиликатного $Н O H$-пакета (рис. 4).

Трансформация мурманита в селивановаит, вероятно, происходила при переработке мурманитсодержащих эвдиалитовых луявритов высококальциевыми растворами, сформировавшимися в ходе фенитизации оливиновых базальтов и их туфов (Korchak et al., 2011), обогащенных титаномагнетитом, ильменитом и рутилом (в пределах Аллуайвского участка Ловозёрского эвдиалитового месторождения обнаружено большое число таких ксенолитов с высокой степенью метасоматической переработки):

$3 \mathrm{An}+6 \mathrm{Di}+2 \mathrm{Ilm}+\left(2 \mathrm{H}_{2} \mathrm{O}+6 \mathrm{~K}^{+}\right) \rightarrow 4 \mathrm{Or}+2 \mathrm{Phl}+9 \mathrm{Ca}^{2+}+2 \mathrm{Fe}^{2+}+2 \mathrm{Ti}^{4+}$ (фенитизация базальтов); $4 \mathrm{Mur}+\left(14 \mathrm{H}_{2} \mathrm{O}+2 \mathrm{Ca}^{2+}+2 \mathrm{Fe}^{2+}\right)=2 \mathrm{Sel}+3 \mathrm{H}_{2}+4 \mathrm{Na}^{+}$(образование селивановаита), 


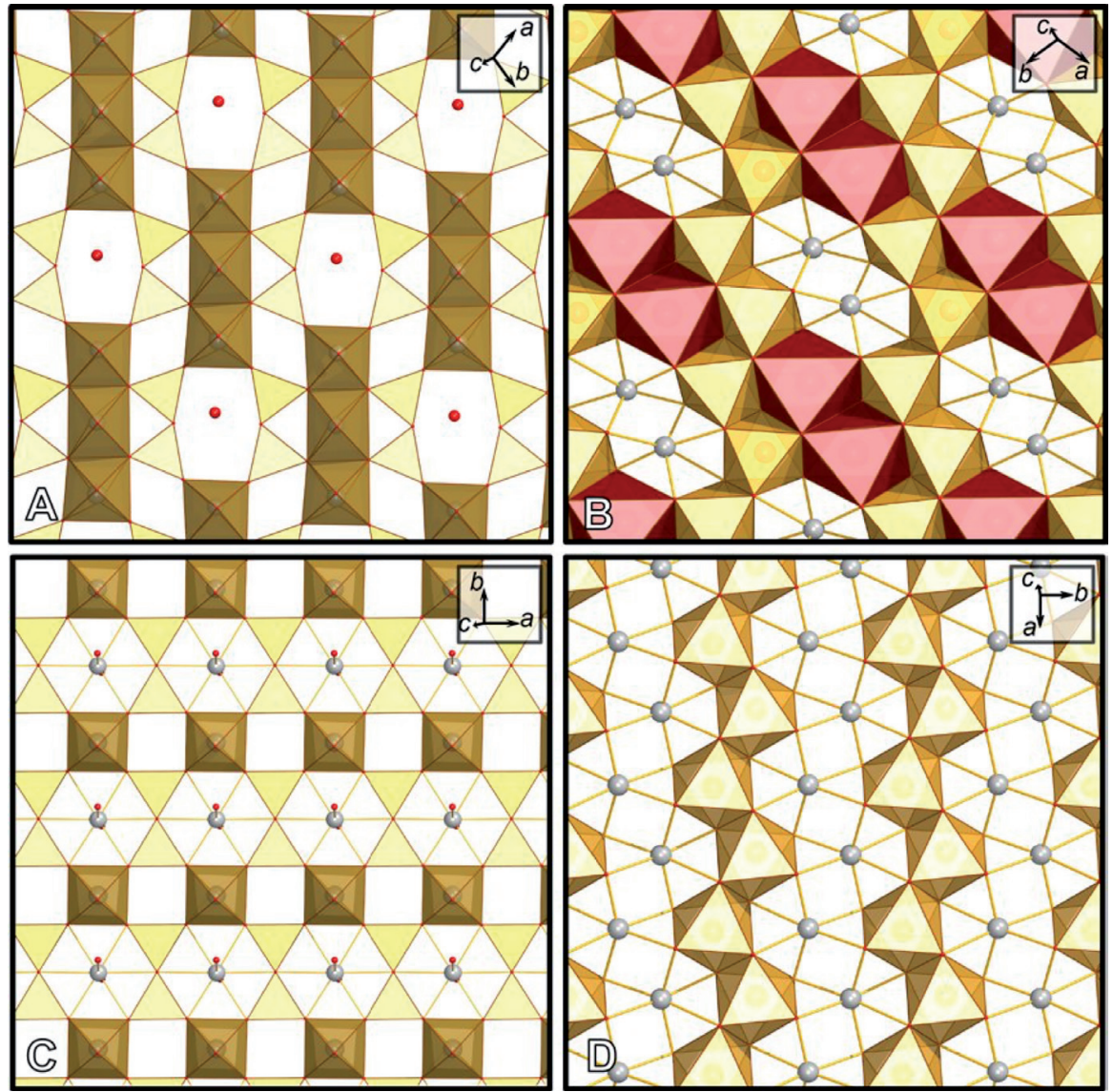

Рис. 4. Гетерополиэдрический $H(\mathrm{~A}, \mathrm{C})$ и октаэдрический $O(\mathrm{~B}, \mathrm{D})$ слои в кристаллических структурах селивановаита $(\mathrm{A}, \mathrm{B})$ и мурманита $(\mathrm{C}, \mathrm{D})$. Наполовину заселённые позиции $M^{0} 4$ и $A^{P} 1$ показаны серыми шариками, $\mathrm{SiO}_{4}$-тетраэдры - жёлтые, $M^{H} 1, M^{H} 2, M^{H} 3$ октаэдры - бледно-коричневые, $M^{O} 1, M^{O} 2$ октаэдры - оранжевые, $M^{3} 3$ октаэдры - красные.

Fig. 4. Structure of heteropolyhedral ( $H$-sheet) $(\mathrm{A}, \mathrm{C})$ and octahedral $(O$-sheet) $(\mathrm{B}, \mathrm{D})$ layers in the crystal structure of selivanovaite (A, B) and murmanite (C, D). Half-occupated $M^{O} 4$ and $A^{P} 1$ sites are represented by grey spheres, $\mathrm{SiO}_{4}$ tetrahedra are in yellow, $M^{H} 1, M^{H} 2, M^{H} 3$ octahedra - pale brown, $M^{O} 1, M^{O} 2$ - orange, $M^{O} 3$ - red.

где $\mathrm{An}$ - анортит, $\mathrm{Di}$ - диопсид, $\mathrm{Ilm}$ - ильменит, Mur - мурманит, $\mathrm{Na}_{4} \mathrm{Ti}_{4} \mathrm{Si}_{4} \mathrm{O}_{18} \bullet 4 \mathrm{H}_{2} \mathrm{O}$, Or - ортоклаз, $\mathrm{Phl}$ - флогопит, $\mathrm{Sel}$ - селивановаит, $\mathrm{Na}_{2} \mathrm{CaFeTi}_{4} \mathrm{Si}_{4} \mathrm{O}_{17}(\mathrm{OH})_{5} \cdot 7 \mathrm{H}_{2} \mathrm{O}$. Для трансформации мурманита в селивановаит одна половина позиций Na в его $H$-слое должна быть заменена на позиции $\mathrm{Ti}$ и $\mathrm{Fe}^{3+}$, тогда как вторая половина должна стать вакантной. В результате такой перестройки, примыкающие к октаэдрическим полиэдрам кремнекислородные диортогруппы $\left[\mathrm{Si}_{2} \mathrm{O}_{7}\right]$, разворачиваются относительно общей вершины. Для окончательного выяснения природы селивановаита планируются эксперименты по гидротермальному изменению мурманита под воздействием высококальциевых железистых растворов.

Исследования проводились в рамках научных тем ФИЦ КНЦ РАН 0226-2019-0009, 0226-2019-0051 и 0186-2019-0011 при финансовой при поддержке Президиума РАН (Программы $35,48)$, РНФ (грант 16-17-10173) и РФФИ (грант 18-29-12039).

\section{Литература}

1. Korchak Yu.A., Men'shikov Yu.P., Pakhomovskii Ya.A., Yakovenchuk V.N., Ivanyuk G.Yu. Trap Formation of the Kola Peninsula // Petrology. 2011. V. 19(1). C. 87-101.

2. Pakhomovsky Y.A., Panikorovskii T.L., Yakovenchuk V.N., Ivanyuk G.Y., Mikhailova J.A., Krivovichev S.V., Bocharov V.N., Kalashnikov A.O. Selivanovaite, $\mathrm{NaTi}_{3}(\mathrm{Ti}, \mathrm{Na}, \mathrm{Fe}, \mathrm{Mn})_{4}\left[\left(\mathrm{Si}_{2} \mathrm{O}_{7}\right)_{2} \mathrm{O}_{4}\left(\mathrm{OH}, \mathrm{H}_{2} \mathrm{O}\right)_{4}\right] \bullet \mathrm{nH}_{2} \mathrm{O}$, a new rock-forming mineral from the eudialyte-rich malignite of the Lovozero alkaline massif (Kola Peninsula, Russia). Eur. J. Mineral. 2018. V. 30. P. 525-535. doi:10.1127/ejm/2018/0030-2740. 